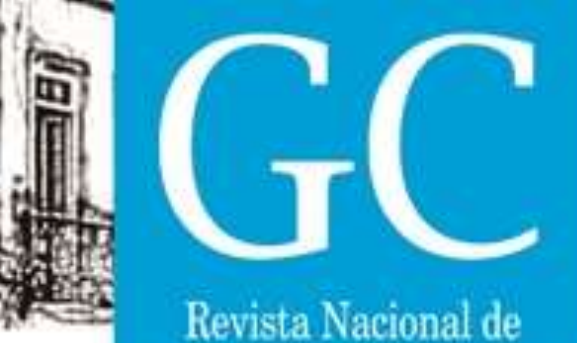

ISSN $2818-8472$

Revista Nacional de

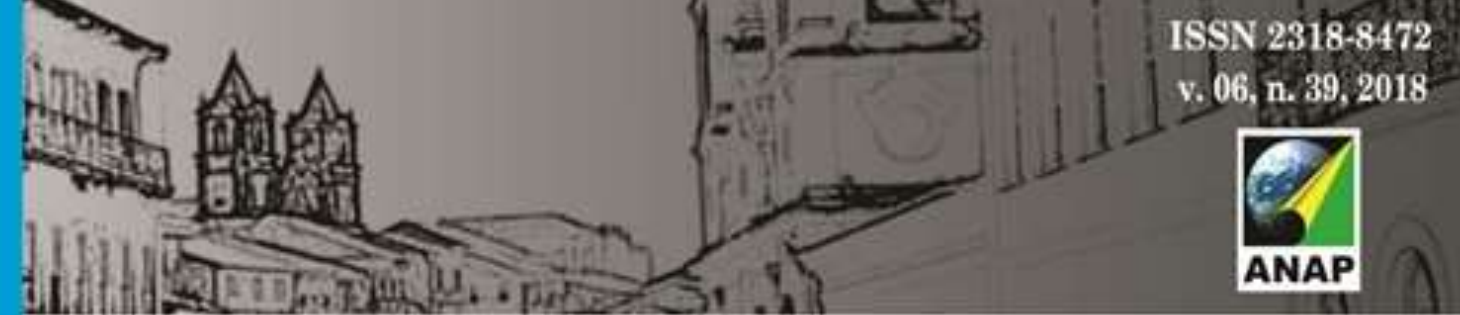

Gerenciamento de Cidades

\title{
Repertório vegetal da arborização urbana do Estado de São Paulo no início do Século XX
}

Repertorio vegetal de la arborización urbana del Estado de São Paulo a principios del siglo XX

Repertory of the urban arborization of the State of São Paulo at the beginning of the 20th Century

Laís Bim Romero Mestranda PPGARQ, UNESP, Brasil Ibimromero@gmail.com

Marta Enokibara Professora PPGARQ, UNESP, Brasil marta@faac.unesp.br 


\section{RESUMO}

A investigação sobre o repertório vegetal que foi utilizado nas praças, jardins, parques e particularmente na arborização urbana das cidades paulistas do início do século XX, enfrenta um duplo problema: a escassez de projetos com a especificação da vegetação e sua identificação botânica. A documentação relativa ao Serviço de Distribuição de Mudas e Sementes (SDMS) do Governo do Estado de São Paulo vem sanar parte dessa lacuna, pois possibilita averiguar o repertório vegetal disseminado. O arco temporal estudado abarca 5.762 "Cartas" de solicitações de mudas e sementes requeridas no período de 1909 a 1912 . Visando à identificação botânica, a pesquisa selecionou as espécies que foram enviadas por seu nome científico, quantificou-as; atualizou a nomenclatura botânica e levantou as cidades que as receberam. O material processado possibilitou, também, mapear essa rede de cidades, onde ficou evidenciada sua relação com o avanço ferroviário.

Palavras chave: arborização urbana, nomenclatura botânica, estado de São Paulo

\section{ABSTRACT}

The research on the vegetable repertoire that was used in squares, gardens, parks and particularly in the urban arborization of the cities of São Paulo in the early twentieth century, faces a double problem: the scarcity of projects with the specification of the vegetation and its botanical identification. The documentation related to the Seeds and Seed Distribution Service (SDMS) of the Government of the State of São Paulo comes to remedy part of this gap, since it makes it possible to ascertain the disseminated plant repertoire. The temporal arch studied covered 5,762 "Letters" of requests for seedlings and seeds required in the period 1909 to 1912. Aiming the botanical identification, the research selected the species that were sent by their scientific name, quantified them; updated the botanical nomenclature and raised the cities that received them. The processed material also made it possible to map this network of cities, where it was evidenced its relation with the railway advance.

Keywords: urban forestry, botanical nomenclature, state of São Paulo

\section{RESUMEN}

La investigación sobre el repertorio vegetal que se utilizó en las plazas, jardines, parques y particularmente en la arborización urbana de las ciudades paulistas de principios del siglo XX, se enfrenta a un doble problema: la escasez de proyectos con la especificación de la vegetación y su identificación botánica. La documentación relativa al Servicio de Distribución de Muelas y Semillas (SDMS) del Gobierno del Estado de São Paulo viene a sanar parte de esa laguna, pues posibilita averiguar el repertorio vegetal diseminado. El arco temporal estudiado abarca 5.762 "Cartas" de solicitudes de mudas y semillas requeridas en el período de 1909 a 1912. Para la identificación botánica, la investigación seleccionó las especies que fueron enviadas por su nombre científico, las cuantificó; actualizó la nomenclatura botánica y levantó las ciudades que las recibieron. El material procesado posibilitó, también, mapear esa red de ciudades, donde quedó evidenciada su relación con el avance ferroviario.

Palabras clave: arborización urbana, nomenclatura botánica, estado de São Paulo 


\section{INTRODUÇÃO}

O arco temporal que abarca a denominada Primeira República (1899-1930) é um período privilegiado de estudo para a história do paisagismo paulista por concentrar várias inovações no campo projetual: a criação da primeira ideia de boulevard, com a construção da Avenida Paulista em 1892; a intensa arborização do período, com a chamada "arborização de alinhamento"; a criação dos primeiros parques públicos (da Avenida Paulista, do Anhangabaú e do Carmo); a criação dos primeiros "bairros jardins" (Jardim Europa, Jardim América); a remodelação de uma série de jardins e praças públicas sob a influência do estilo paysager ou do chamado "jardim paisagístico francês" (DOURADO, 2011); além da proposta de um sistema de parques e parkways (MAIA, 1930). Vários foram os paisagistas e urbanistas responsáveis por essas inovações, o que traz um rico universo comparativo para aferir a circulação transnacional desses novos repertórios vegetais e paisagísticos na construção do território paulista.

Entretanto, a principal dificuldade para o estudo desses jardins, praças, parques e a arborização do período diz respeito ao repertório vegetal utilizado. Apesar da existência de vários catálogos de plantas que circulavam na capital paulista desde o final do século XIX, entre eles os da firma Estabelecimento Floricultura, fundada em 1893 pelo alemão Johann Dierberger (ENOKIBARA, 2016), são raros os documentos encontrados até o momento com a identificação das espécies utilizadas nos projetos e mais rara ainda sua identificação botânica.

Guaraldo, em sua dissertação (1995) e posteriormente em sua tese (2002) estudou detalhadamente a capital paulista nesse período, recorrendo principalmente aos Relatórios Anuais de Prefeitos que, segundo a autora, descreviam as espécies que estavam sendo utilizadas na arborização urbana. Mas e o restante das cidades paulistas? A Primeira República também foi o período de grande expansão em direção ao chamado "Oeste Paulista" que, ensejado pelo prolongamento das ferrovias (Araraquarense, Paulista, Noroeste e Sorocabana) propiciou a formação de uma série de cidades (MONBEIG,1984). Esse foi o recorte territorial de estudo de uma equipe de professores da Unesp-Bauru que participou de um Projeto Temático FAPESP, sob a coordenação geral da Profa. Dra. Maria Stella Martins Bresciani (IFCH-Unicamp), no período de 2006 a 2011, cujos resultados já foram publicados em congressos e artigos.

Um dos materiais trabalhados durante o Projeto Temático e que até hoje é objeto de pesquisa são os documentos relativos ao Serviço de Distribuição de Mudas e Sementes (SDMS); cuja catalogação, transcrição e sistematização já foram feitas por bolsistas de iniciação científica (ZECHINATO, 2008; YENDO, 2011; ROMERO, 2012; MODESTO, 2012).

O presente artigo é o resultado de mais uma etapa de investigação deste material - a identificação das espécies descritas por seu nome científico, que é parte integrante da dissertação em andamento de Laís Bim Romero, iniciada em 2017 e denominada "Serviço de Distribuição de Mudas e Sementes. O fomento à arborização urbana do Estado de São Paulo no início do século XX" (título provisório), junto ao Programa de Pós-Graduação em Arquitetura e Urbanismo da Faculdade de Arquitetura, Artes e Comunicação da Universidade Estadual Paulista "Júlio de Mesquita Filho", campus de Bauru. 


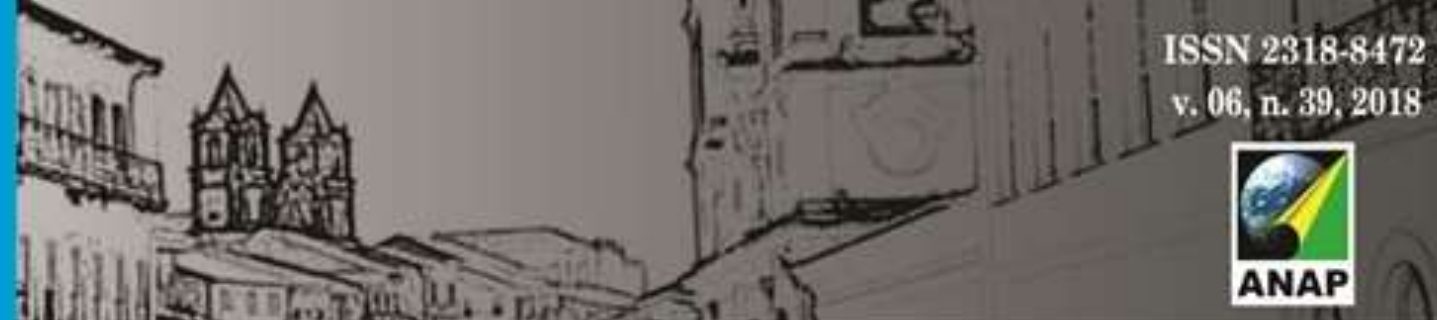

Gerenciamento de Cidades

\section{OBJETIVOS}

O objetivo deste artigo é apresentar os resultados alcançados quanto às espécies solicitadas pelo nome científico ao SDMS entre 1909 e 1912. Além da identificação, será exposta sua quantificação, a atualização botânica dos nomes, a identificação da rede de cidades atendidas e sua espacialização cartográfica juntamente com a rede ferroviária.

\section{METODOLOGIA}

O artigo está estruturado em três partes. A primeira traz um breve resumo da criação do Serviço de Distribuição de Mudas e Sementes do Governo do Estado de São Paulo; a caracterização das "Cartas" de solicitações de mudas e sementes; a forma como o material foi organizado e o problema da nomenclatura botânica. A segunda parte traz a relação das espécies solicitadas pelo nome científico, a quantificação das arbóreas segundo seu requerente - público ou privado - e a atualização da nomenclatura botânica. A terceira parte identifica as cidades que solicitaram mudas pelo nome científico e as insere na cartografia do estado sobrepondo à rede ferroviária existente.

\section{O SERVIÇO DE DISTRIBUIÇÃO DE MUDAS E SEMENTES (SDMS)}

\subsection{A CRIAÇÃO DO SDMS}

Logo após a Proclamação da República, o governo do Estado de São Paulo criou a Secretaria de Agricultura, Comércio e Obras Públicas, através da Lei no 15 de 11 de novembro de 1891 e posteriormente regulamentada pelo Decreto no 28 de 01 de março de 1892. Nesse mesmo ano incorporou uma das principais instituições agrícolas do país, a Imperial Estação Agronômica (fundada em 1886), passando a ser denominado Instituto Agronômico do Estado (IAE) e na sequencia, Instituto Agronômico de Campinas (IAC). Nos primeiros Relatórios Anuais da Secretaria de Agricultura, Comércio e Obras Públicas há registros da distribuição, ainda discreta, de sementes - em maior parte agrícolas - e de mudas de diferentes espécies de eucaliptos. Estas provinham, em sua maioria, do IAE e eram distribuídas a Câmaras Municipais e a particulares, por ordem da Secretaria da Agricultura.

A crescente procura de mudas e sementes por agricultores de todo o Estado, visando à renovação e ao ensaio de novas culturas, fez com que a Secretaria tivesse seus gastos elevados ao ter que recorrer a terceiros para atender aos inúmeros pedidos. Segundo o Relatório de 1898, esse fator apenas ratificava a necessidade e a importância de implantar-se um Serviço de Distribuição de Mudas e Sementes organizado e que dispusesse de verba e equipe técnica própria. Assim, o governo criou em 1899, por meio da Lei ${ }^{\circ}$ 678 de 13 de setembro, o Serviço Agronômico, e subordinado a ele, o Serviço de Distribuição de Mudas e Sementes (SDMS), ambos regulamentados por meio do Decreto $\mathrm{n}^{\circ} 752$ de 15 de março de 1900.

Para suprir a demanda de solicitações, o governo autorizou o recém-criado Horto Botânico de São Paulo (1896) a auxiliar o IAE na produção e distribuição. Desse modo, as duas instituições passaram a atender o público em geral com mudas e sementes de plantas de utilidade e também de ornamentação. 


\subsection{A CLASSIFICAÇÃO DAS “CARTAS DE ENVIO" DO SDMS E AS DISTINÇÕES ENTRE REQUERENTES PÚBLICOS E PRIVADOS}

As plantas e sementes enviadas eram registradas em papéis timbrados do Serviço de Distribuição de Mudas e Sementes, assinados pelo diretor da instituição e com informações acerca do nome do solicitante, data, localidade de destino, espécies solicitadas e suas quantidades. Esses registros foram denominados "Cartas de Envio" na catalogação e sistematização do material feita pelas bolsistas de iniciação científica supracitada.

Lamentavelmente, apenas as Cartas relativas aos envios realizados pelo IAE foram localizadas, tornando o livro "Notas sobre Plantas Exóticas Introduzidas no Estado de São Paulo", escrito em 1906, pelo botânico e então diretor do Horto, Alberto Löfgren, o único registro, até o momento, das espécies que estavam sendo ensaiadas e distribuídas pelo Horto Botânico de São Paulo. No livro constam ainda citações das espécies que estavam, concomitantemente, sendo distribuídas e ensaiadas pelo IAE, mas não há a referência das cidades que recebiam mudas e sementes ou as quantidades enviadas (GONÇALVES, 2014).

As Cartas de Envio do IAE, localizadas na biblioteca do Instituto, estão agrupadas em 48 volumes que abarcam as distribuições feitas entre 1905 e 1914. Porém o elevado grau de deterioração do material, bem como suas lacunas temporais, restringiram as análises ao período de 1909 a 1912, compreendendo 21 volumes, com periodicidade praticamente ininterrupta.

Como exposto em trabalhos precedentes (ENOKIBARA et. al, 2016), as "Cartas de Envio" eram emitidas em duas vias - Tipo A e Tipo B. Enquanto a última foi intitulada "Carta de Solicitação de Despacho", pois era comumente destinada ao chefe da estação por onde o pedido seria encaminhado; a primeira foi nomeada "Carta de Despacho Geral", pois trazia informações sobre a data da solicitação, o nome do requerente, a localidade de destino (cidade, estação ou núcleo colonial), a data do despacho, as espécies solicitadas e suas quantidades, tornando-se, por isso, o documento de interesse a este estudo.

Nos 21 volumes correspondentes aos anos de 1909 a 1912, estão compiladas 5.825 Cartas do Tipo A, que puderam ser divididas em grupos classificados conforme seus solicitantes em: "públicos" (440 cartas), "privados" (5.322 cartas) e "outros" (63 cartas).

Dentre esses requerentes, segundo Enokibara et. al (2016), os pedidos do grupo "público" envolviam órgãos, instituições e cargos públicos; enquanto os agrupados em "privados" abarcavam pessoas, órgãos, empresas, instituições particulares e nomes relacionados à Igreja (cônego, seminário, padre, reverendo).

Já os requerentes identificados como "outros" foram revistos como parte das pesquisas da supracitada dissertação de mestrado em andamento. Além das cartas ilegíveis; "sem efeito", sem identificação de requerente e com informações insuficientes (ENOKIBARA et al, 2016); passaram também a compor essa categoria os pedidos realizados por pessoas que se identificavam pelo título de "coronel", "capitão" ou "major". Na época esses títulos eram utilizados indistintamente, tanto referindo-se ao ambiente de trabalho, quanto à pessoa física, o que impossibilita a exata identificação dos requerentes. 


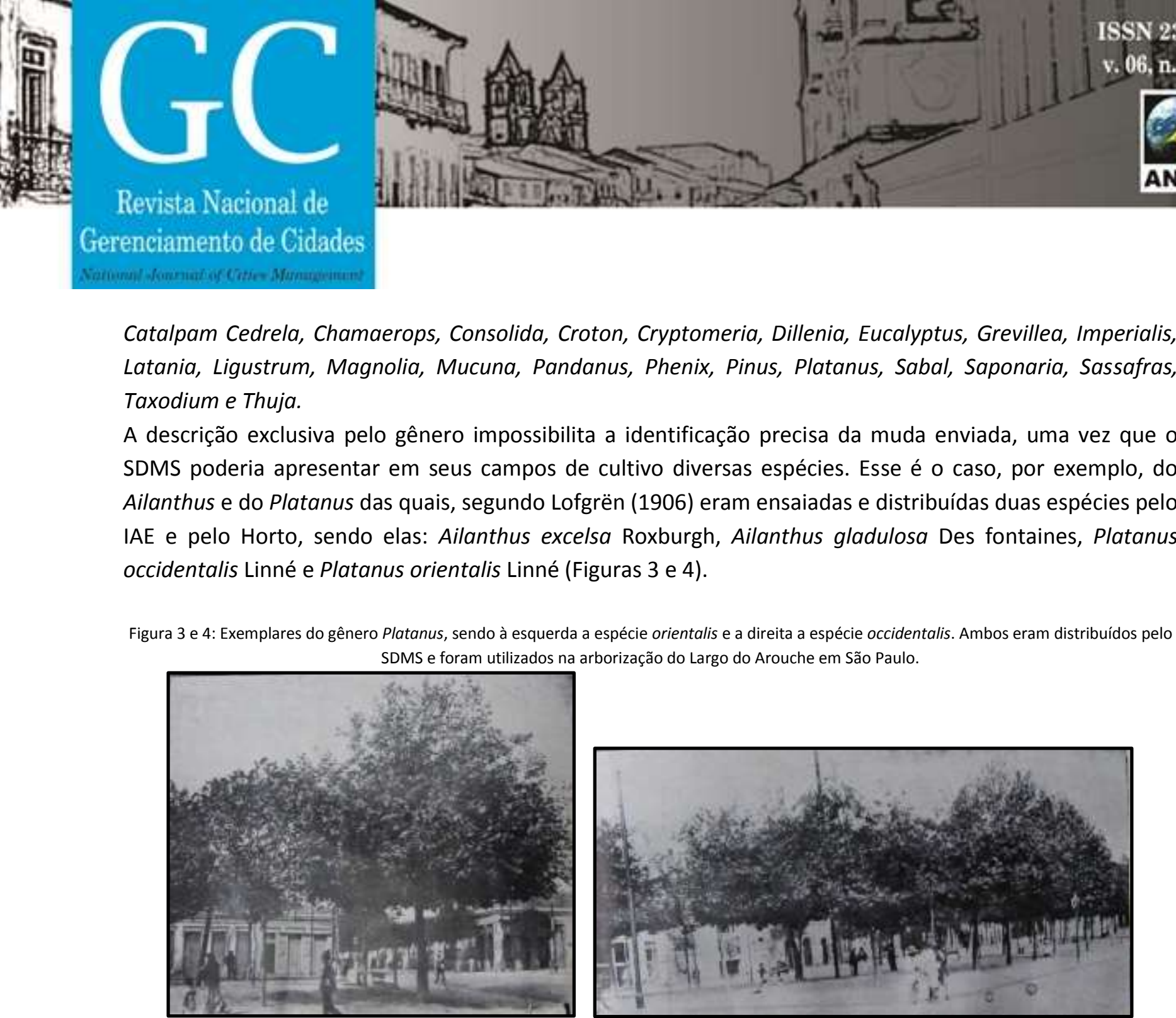

Catalpam Cedrela, Chamaerops, Consolida, Croton, Cryptomeria, Dillenia, Eucalyptus, Grevillea, Imperialis, Latania, Ligustrum, Magnolia, Mucuna, Pandanus, Phenix, Pinus, Platanus, Sabal, Saponaria, Sassafras, Taxodium e Thuja.

A descrição exclusiva pelo gênero impossibilita a identificação precisa da muda enviada, uma vez que o SDMS poderia apresentar em seus campos de cultivo diversas espécies. Esse é o caso, por exemplo, do Ailanthus e do Platanus das quais, segundo Lofgrën (1906) eram ensaiadas e distribuídas duas espécies pelo IAE e pelo Horto, sendo elas: Ailanthus excelsa Roxburgh, Ailanthus gladulosa Des fontaines, Platanus occidentalis Linné e Platanus orientalis Linné (Figuras 3 e 4).

Figura 3 e 4: Exemplares do gênero Platanus, sendo à esquerda a espécie orientalis e a direita a espécie occidentalis. Ambos eram distribuídos pelo SDMS e foram utilizados na arborização do Largo do Arouche em São Paulo.

Fonte: Revista O Fazendeiro (1912, p. 364 e 365).

\section{RELAÇÃO DE ESPÉCIES SOlICITADAS PELO NOME CIENTíFICO E ATUALIZAÇÃO dA NOMENCLATURA BOTÂNICA}

\subsection{RELAÇÃO DE ESPÉCIES SOLICITADAS PELO NOME CIENTÍFICO}

Nos pedidos de requerentes públicos e privados, entre os anos de 1909 e 1912, foram levantados 49 nomes científicos (gêneros e espécie) utilizados nas solicitações, sendo que nenhum dispunha da indicação da autoridade botânica responsável por sua identificação.

Conforme classificação de Löfgren (1906), dos nomes levantados, três eram de espécies arbustivas, quatro de palmeiras, nove de plantas ornamentais utilizadas para adorno de jardins e 34 de espécies arbóreas (Tabela 1). 


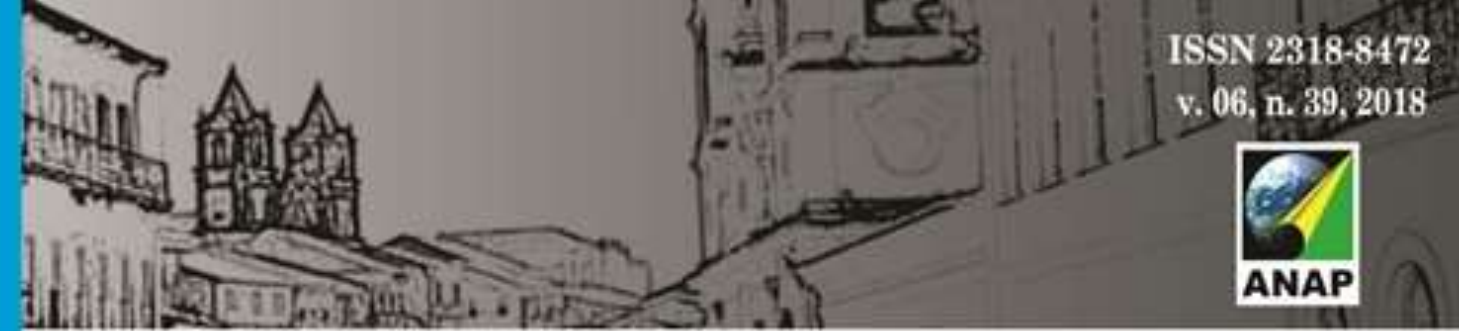

Gerenciamento de Cidades

Tabela 1: Relação de nomes científicos constantes nas Cartas de Envio do IAE entre os anos de 1909 e 1912.

\begin{tabular}{|c|c|c|}
\hline \multicolumn{3}{|c|}{ ARBUSTIVAS } \\
\hline Bixa orellana & Casuarina glauca & Grevilea forsteri \\
\hline \multicolumn{3}{|c|}{ PALMEIRAS } \\
\hline Caryota urens & Latania borbonica & Phoenix dactylifera \\
\hline Caryota mitis & & \\
\hline \multicolumn{3}{|c|}{ ORNAMENTAIS } \\
\hline Ficus repens & Musa speciosa & Pandanus javanicus \\
\hline Musa ensete & Pandanus javanicus & Phormium tenax \\
\hline Musa religiosa & Pandanus utilis & Vicia villosa \\
\hline \multicolumn{3}{|c|}{ ARBÓREAS } \\
\hline Ailanthus glandulosa & Eucalyptus gomphocephala & Grevilea robusta \\
\hline Araucaria brasiliensis & Eucalyptus hemiphloria & Ligustrum japonicum \\
\hline Araucaria excelsa & Eucalyptus longifolia & Melia azedarach \\
\hline Caesalpinia echinata & Eucalyptus pimetata & Pinus canariensis \\
\hline Cedrela brasiliensis & Eucalyptus punctata & Pinus halepensis \\
\hline Ceratonia siliqua & Eucalyptus resinifera & Pinus maritima \\
\hline Colvillea festeri & Eucalyptus robusta & Pinus pinea \\
\hline Cryptomeria japonica & Eucalyptus rostrata & Platanus orientalis \\
\hline Cupressus pyramidalis & Eucalyptus siderophloia & Sophora japonica \\
\hline Dillenia speciosa & Eucalyptus tereticornis & Taxodium pyramidatum \\
\hline Eucalyptus citriodora & Ficus elastica & Thuja occidentalis \\
\hline Eucalyptus globulus & & \\
\hline
\end{tabular}

Fonte: Elaborado pelas autoras (2018).

\subsection{QUANTIFICAÇÃO DAS ESPÉCIES ARBÓREAS SOLICITADAS PELO NOME CIENTÍFICO}

Tendo em vista que o foco principal desta pesquisa recai sobre as espécies destinadas à arborização urbana, foram excluídas da contagem as arbustivas, as palmeiras e as ornamentais.

Constatou-se que no arco temporal estudado as espécies arbóreas eram comumente solicitadas ao IAE na forma de mudas, com exceção de algumas silvícolas requeridas unicamente por sementes, conforme indicado e quantificado na Tabela 2, abaixo. 


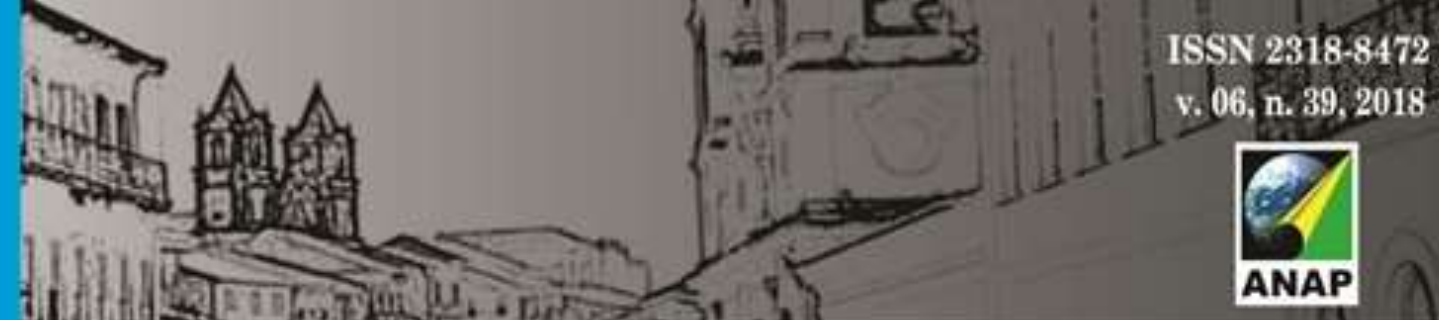

Gerenciamento de Cidades

As três espécies de mudas (excluindo-se os pedidos de sementes) mais solicitadas são bastante heterogêneas, uma vez que a mais requerida - Eucalyptus robusta - é classificada como silvícola; a segunda mais pedida - Cedrela brasiliensis - é uma espécie nativa brasileira; e a terceira - Ailanthus glandulosa - é uma espécie exótica introduzida no país, o que demonstra o amplo repertório que o SDMS possuía e disseminava pelo Estado.

O Eucalyptus robusta (Figura 5) destaca-se pela quantidade de mudas enviadas. É a espécie mais solicitada por requerentes privados (2043 mudas) e a terceira mais pedida por públicos (404 mudas). A esta se deve acrescer a quantificação das mudas de Eucalyptus rostrata (197 para públicos e 265 para privados), uma vez que as duas espécies são tidas como sinonímia botânica, ou seja, correspondem a uma mesma planta que recebeu duas denominações distintas, propostas por autoridades botânicas diferentes, vindo a prevalecer a que foi descrita primeiramente.

Assim, a somatória das espécies (E. robusta e E. rostrata) resulta em 2909 mudas enviadas durante os quatro anos da pesquisa, ratificando a informação contida no livro que comemora o cinquentenário da Secretaria da Agricultura, onde Schmidt e Reis (1943) descrevem que o Eucalipto foi a principal essência distribuída pelo SDMS durante vários anos, principalmente a partir de 1911, quando nos totais de mudas fornecidas suas porcentagens variavam entre 64 e $91 \%$.

Os autores apontam ainda que o crescimento nas solicitações da espécie silvícola reflete o incentivo ao reflorestamento por parte do Estado, tendo em vista que a derrubada das matas para obter-se lenha vinha acontecendo de forma desenfreada, resultante da necessidade de combustível (carvão) para abastecer ferrovias, fábricas e particulares, prejudicados pelas dificuldades de transportes ocasionadas pela guerra.

Löfgren (1906) citava que essa espécie tinha um incontestável valor para o serviço florestal, por apresentar crescimento rápido e ser resistente às geadas, prosperar em brejos onde quase nenhuma espécie sobrevivia e ser "talvez a espécie mais conhecida na Capital e seus arredores onde fructifica abundantemente, o que é prova da sua perfeita aclimatação" (p. 100).

Figura 5: Plantação de Eucalyptus robusta com idade de dois anos e meio.

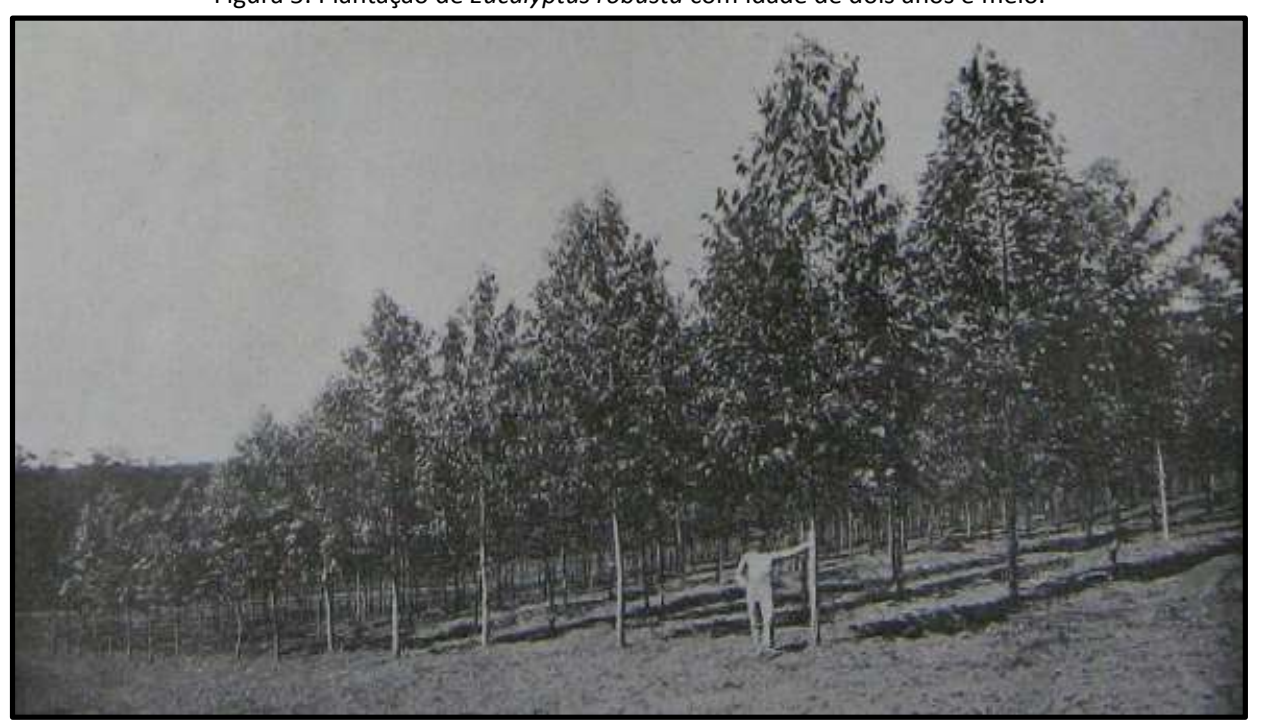

Fonte: Revista O Fazendeiro (1909, p. 139). 


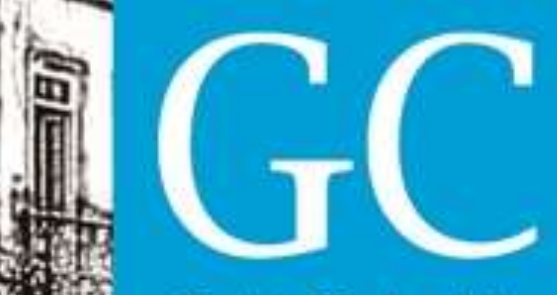

Revista Nacional de

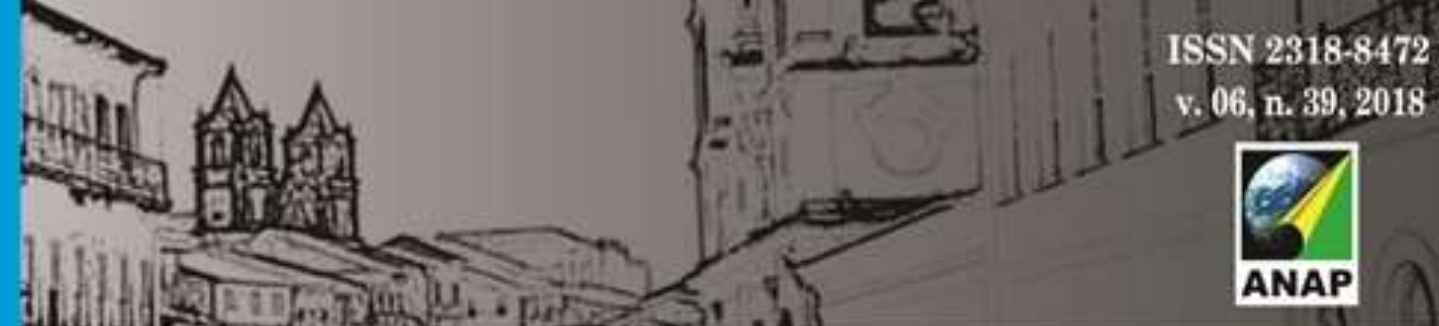

Gerenciamento de Cidades

A segunda com maior número de pedidos (1449 mudas) foi a Cedrella brasiliensis, sendo a espécie mais solicitada entre os requerentes públicos (945 mudas) e a terceira entre os privados (504 mudas). Guaraldo (2002) aponta que essa arbórea esteve presente na arborização urbana da capital paulista entre os anos de 1900 e 1904, aparecendo também, anos depois, na arborização de praças do interior do Estado, como é o caso da Praça de São Benedito na cidade de Jaboticabal (Figura 6), apontada por Zechinato (2008).

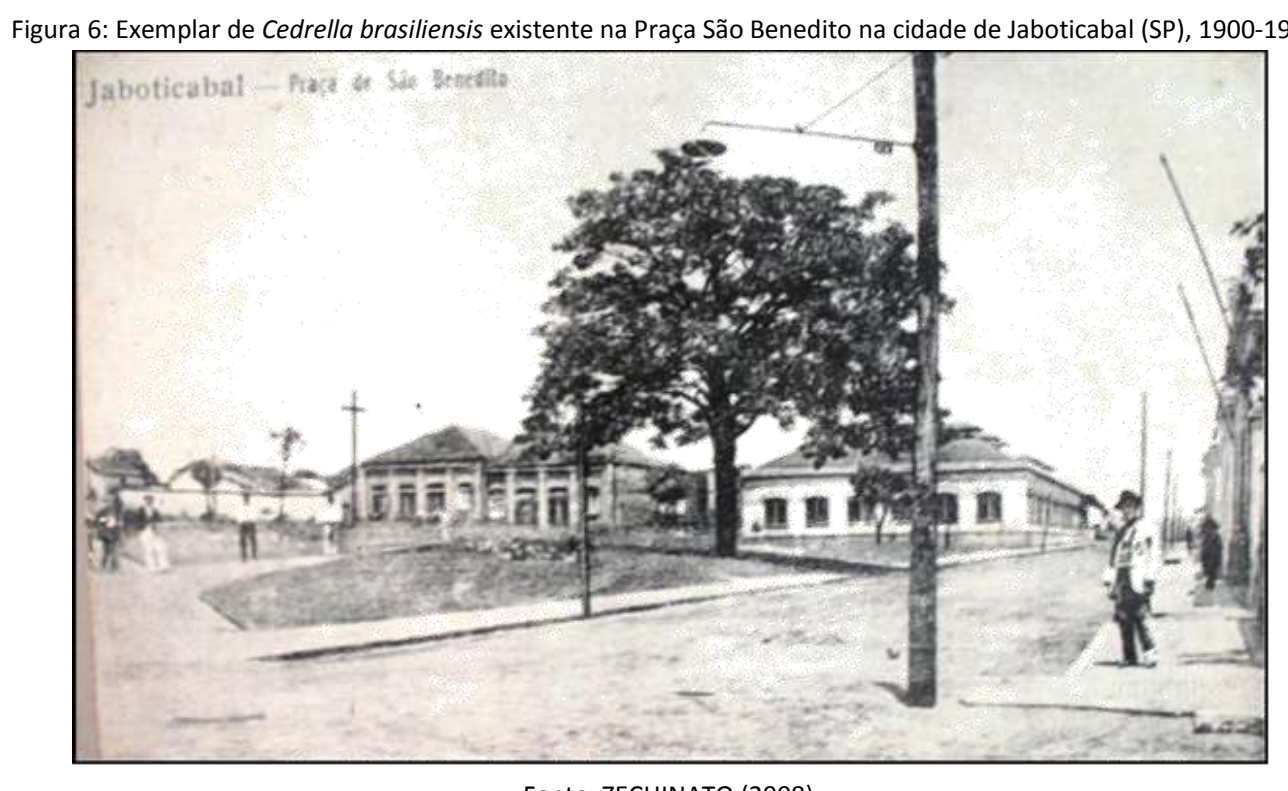

Por fim, a Ailanthus glandulosa aparece como a terceira espécie com maior numero de solicitações (752 mudas). Entre os solicitantes públicos, aparece como a segunda mais pedida (500 mudas) e entre os requerentes privados aparece em sexto lugar (252 mudas). Löfgren (1906) relata que a espécie é originária da Índia, de grande porte, passando dos 20 metros de altura e, segundo o autor, assemelha-se ao "Jequitibá brasileiro". O botânico ainda cita que a espécie já vinha sendo distribuída pelo Instituto Agronômico, e o Horto passaria a cultivar vastas sementeiras da espécie, uma vez que a mesma era bastante recomendável por apresentar um rápido crescimento e estar aclimatada em São Paulo.

\subsection{ATUALIZAÇÃO DA NOMENCLATURA BOTÂNICA}

Com a organização dos dados sobre as espécies vegetais, verificou-se que além de os nomes científicos não terem a autoridade botânica em sua nomenclatura, alguns estavam desatualizados. Na Tabela 4, constam os nomes científicos tal qual a grafia descrita nas Cartas de Envios (sem a autoridade botânica) e, ao lado, a nomenclatura botânica aceita, atualizada segundo a base de dados The Plant List (2013). 


\section{CIDADES QUE SOLICITARAM MUDAS E SUA RELAÇÃO COM A REDE FERROVIÁRIA}

\subsection{CIDADES QUE SOLICITARAM ESPÉCIES ARBÓREAS PELO NOME CIENTÍFICO}

Foram relacionadas todas as cidades, estações e núcleos coloniais que realizaram pedidos dessas espécies arbóreas ao IAE, utilizando-se, não do nome popular, mas sim do nome cientifico, o que resultou em uma listagem de 129 localidades (Tabela 5), distribuídas pelo território paulista no período de 1909 a 1912.

Tabela 5: Relação de cidades que realizaram solicitações de espécies arbóreas pelo nome científico, entre os anos de 1909 e 1912 ao IAE.

\begin{tabular}{|c|c|c|c|}
\hline \multicolumn{4}{|c|}{ CIDADES QUE REALIZARAM SOLICITAÇÕES AO IAE DE ESPÉCIES ARBÓREAS PELO NOME CIENTíFICO } \\
\hline $\begin{array}{c}\text { Aguaí } \\
\text { (Cascavel) }\end{array}$ & Conchas & $\begin{array}{c}\text { Jardinopolis } \\
\text { (Visconde de Parnahyba) }\end{array}$ & Queluz \\
\hline $\begin{array}{l}\text { Águas da Prata } \\
\text { (Cascata) }\end{array}$ & $\begin{array}{l}\text { Cordeirópolis } \\
\text { (Cordeiro) }\end{array}$ & $\begin{array}{c}\text { Jarinu } \\
\text { (Campo Largo) }\end{array}$ & $\begin{array}{c}\text { Rafard } \\
\text { (Villa Raffard) }\end{array}$ \\
\hline Agudos & Corumbatahy & $\begin{array}{c}\text { Jaboticabal } \\
\text { (Córrego Rico) }\end{array}$ & $\begin{array}{l}\text { Ribeirão Bonito } \\
\text { (Sampaio Vidal) }\end{array}$ \\
\hline $\begin{array}{c}\text { Americana } \\
\text { (Santa Bárbara, Villa } \\
\text { Americana) }\end{array}$ & $\begin{array}{c}\text { Cosmópolis } \\
\text { (Campos Salles) }\end{array}$ & Jundiaí & Ribeirão Pires \\
\hline Americo Braziliense & Cotia & Leme & $\begin{array}{l}\text { Ribeirão Preto } \\
\text { (Villa Bonfim) }\end{array}$ \\
\hline $\begin{array}{c}\text { Amparo } \\
\text { (Coqueiros) }\end{array}$ & Cravinhos & Limeira & Rincão \\
\hline Anápolis & Descalvado & Lorena & $\begin{array}{l}\text { Rio Claro } \\
\text { (Ferraz) }\end{array}$ \\
\hline Anhembi & Dobrada & $\begin{array}{c}\text { Louveira } \\
\text { (Luiz Gonzaga) }\end{array}$ & Rio das Pedras \\
\hline Araraquara & Espirito Santo do Pinhal & Mandihú & Salles Oliveira \\
\hline $\begin{array}{c}\text { Araras } \\
\text { (São Bento) }\end{array}$ & Espirito Santo do Turvo & Mattão & Santa Cruz das Palmeiras \\
\hline Atibaia & Fartura & Mineiros & Santa Cruz do Rio Pardo \\
\hline Avaré & Faxina & Mococa & Santa Ernestina \\
\hline Bananal & Franca & $\begin{array}{c}\text { Mogi Mirim } \\
\text { (Coselheiro Martim Francisco) }\end{array}$ & $\begin{array}{c}\text { Santa Rita do Passa Quatro } \\
\text { (Santa Rita) }\end{array}$ \\
\hline Barretos & Gavião Peixoto & $\begin{array}{l}\text { Mogy das Cruzes } \\
\text { (Sabaúna) }\end{array}$ & $\begin{array}{l}\text { Santa Rosa do Viterbo } \\
\text { (Ibiquara, Santa Rosa) }\end{array}$ \\
\hline Baruery & Guará & $\begin{array}{l}\text { Mogy-Guassú } \\
\text { (Nova Louzã) }\end{array}$ & Santos \\
\hline
\end{tabular}




\begin{tabular}{|c|c|c|c|}
\hline Batatais & Guaratinguetá & $\begin{array}{c}\text { Monte Alegre do Sul (Carlos } \\
\text { Norberto) }\end{array}$ & $\begin{array}{c}\text { São Carlos } \\
\text { (Água Vermelha, Capão } \\
\text { Preto, Jacaré) }\end{array}$ \\
\hline Bebedouro & $\begin{array}{c}\text { Guariba } \\
\text { (Hammond) }\end{array}$ & Monte Azúl & São João da Boa Vista \\
\hline Boa Esperança & Ibitinga & Nova Europa & São José do Rio Pardo \\
\hline $\begin{array}{c}\text { Bocaina } \\
\text { (Pedro Alexandrino) }\end{array}$ & Igarapava & Nova Odessa & São José dos Campos \\
\hline Boituva & Iguape & Oleo & São Manoel \\
\hline Boreby & Indaiatuba & Orlândia & São Paulo \\
\hline Botucatú & Ipiranga & Osasco & São Pedro \\
\hline Bragança & $\begin{array}{c}\text { Itabera } \\
\text { (Engenheiro Maia) }\end{array}$ & Pederneiras & $\begin{array}{c}\text { São Simão } \\
\text { (Bento Quirino) }\end{array}$ \\
\hline $\begin{array}{c}\text { Brotas } \\
\text { (Espraiado) }\end{array}$ & Itapira & $\begin{array}{l}\text { Pedregulho } \\
\text { (Chapadão) }\end{array}$ & Serra Azul \\
\hline Cajurú & Itararé & Pedreira & Socorro \\
\hline $\begin{array}{c}\text { Campinas } \\
\text { (Arraial dos Sousas, Cabras, } \\
\text { Tanquinho) }\end{array}$ & Itatiba & Pindamonhangaba & Sorocaba \\
\hline $\begin{array}{l}\text { Campos Novos de } \\
\text { Paranapanema }\end{array}$ & Itatinga & Piquete & Tambahú \\
\hline Capão Bonito & Itoby & Piracicaba & Taquaritinga \\
\hline Capivary & Jaboticabal & Pirassununga & Tatuhy \\
\hline $\begin{array}{l}\text { Casa Branca } \\
\text { (Lagôa) }\end{array}$ & Jacareí & Piratininga & Taubaté \\
\hline Catanduva & $\begin{array}{c}\text { Jaguariuna } \\
\text { (Jaguary) }\end{array}$ & Porto Feliz & $\begin{array}{l}\text { Vinhedo } \\
\text { (Rocinha) }\end{array}$ \\
\hline Catiguá (Ibarra) & Jahú & Porto Ferreira & Votuporanga \\
\hline Cerqueira Cesar & & & \\
\hline
\end{tabular}

Como se verifica na Tabela 5, alguns destinos presentes nas Cartas correspondiam a estações ferroviárias e não a cidades e/ou núcleos coloniais. Nestes casos, os nomes das estações encontram-se descritos entre parênteses abaixo das cidades correspondentes à localização dessas estações.

Buscando compreender a rede de cidades abrangidas (Mapa 1), estas foram inseridas no mapa estadual, utilizando-se como mapa base o elaborado em 2014 pelo Instituto Geográfico e Cartográfico (IGC), com o perímetro dos municípios. Salienta-se que, como as cidades pesquisadas são aquelas referentes às solicitações de mudas do ano de 1909 a 1912, as delimitações podem diferir dos perímetros dos municípios desse mapa base de 2014, uma vez que ocorreram incorporações ou desmembramentos de distritos. 


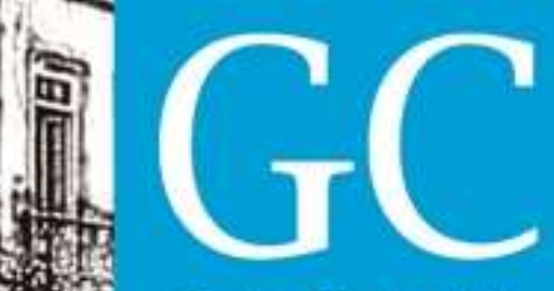

Revista Nacional de

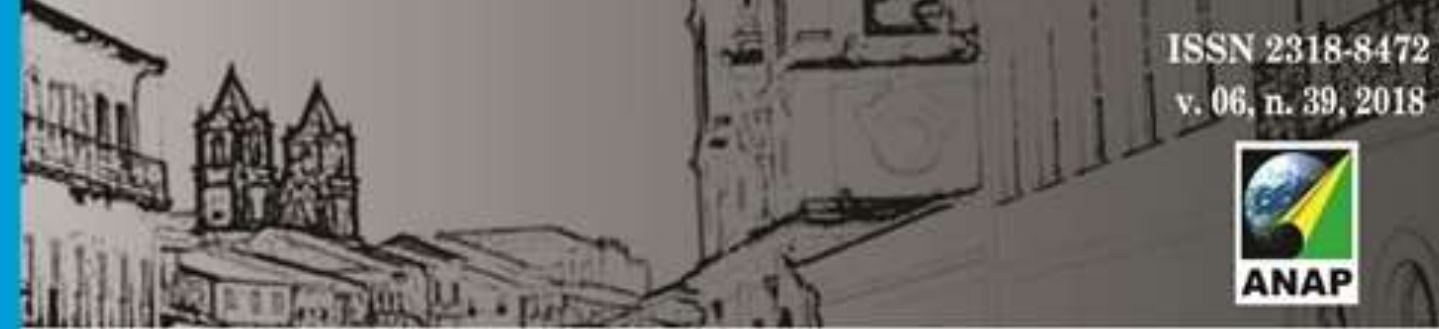

Gerenciamento de Cidades

Outra informação importante a ser considerada diz respeito à demarcação da "cuesta" que aparece nesse mesmo mapa. A linha em tracejado se refere ao limite ocidental da Depressão Periférica e o início da Cuesta, de acordo com a divisão geomorfológica do estado de São Paulo (IPT, 1981).

Mapa 1: Mapa dos municípios do Estado de São Paulo com destaque as localidades que foram destinos das espécies arbóreas solicitadas pelo nome científico ao IAE, por meio do SDMS, entre os anos de 1909 e 1912.

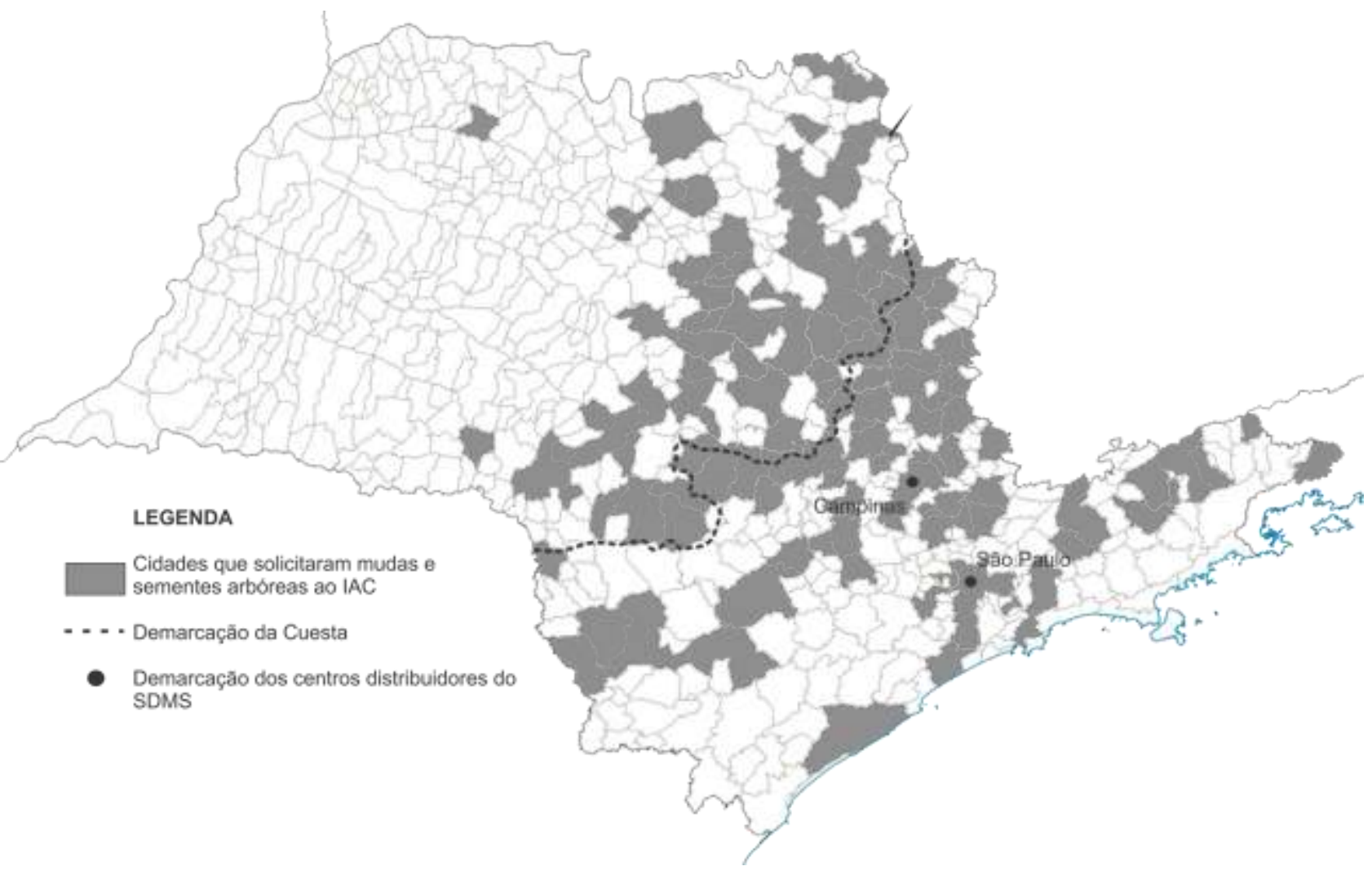

Fonte: Mapa base (2014) disponível em http://www.mapas-sp.com/municipios.htm>, acessado em 23/03/2018. Elaborado pelas autoras (2018).

O resultado alcançado expõe a predominância de solicitações pelo nome científico nas imediações dos centros distribuidores, Campinas e São Paulo, enquanto no extremo oeste, apesar de nesse período constarem várias solicitações, estas eram em sua grande maioria feitas pelo nome popular das espécies, o que não nos permite identificar e atualizar sua nomenclatura botânica.

\subsection{A RELAÇÃO DE CIDADES SOLICITANTES E A REDE FERROVIÁRIA}

Outra informação importante levantada é que, ao inserir no Mapa 1 as principais linhas férreas, torna-se evidente a contribuição das ferrovias na disseminação do repertório arbóreo pelo estado, uma vez que a grande maioria das cidades solicitantes localizava-se ao longo dos trilhos, como demonstrado no Mapa 2. 
Constataram-se também solicitações destinadas aos estados de Santa Catarina (cidade de Laguna) e Rio Grande do Sul (município de Rio Grande) evidenciando o avanço e o alcance do SDMS.

\section{CONSIDERAÇÕES FINAIS}

O levantamento das espécies vegetais distribuídas pelo SDMS por seu nome científico possibilitou identificar 34 espécies arbóreas. Dentre as três mais solicitadas verificou-se uma heterogeneidade: a mais requerida - Eucalyptus robusta, uma espécie silvícola, evidenciando o empenho do governo para o reflorestamento do estado; a segunda mais pedida - Cedrela brasiliensis, uma espécie nativa do Brasil, também evidenciando o empenho principalmente dos botânicos à frente do IAC e do Horto Botânico de São Paulo, para a valorização da flora nativa; e a terceira - Ailanthus glandulosa, exótica, recomendada pelo botânico sueco Alberto Löfgren, diretor do Horto, por já estar aclimatada no estado, ser de grande porte e de rápido crescimento.

Ao identificar as cidades que solicitaram essas espécies e sobrepondo com a rede ferroviária, fica claro o papel desta na distribuição de um repertório vegetal que transpassou as barreiras de São Paulo e influiu na arborização não só dos estados limítrofes (Minas Gerais, Rio de Janeiro e Paraná), mas também do sul do país.

\section{REFERÊNCIAS}

Assembleia Legislativa do Estado de São Paulo. Coleções de Leis do Estado de São Paulo. Disponível em: < https://www.al.sp.gov.br/>. Acesso em: 03 de março de 2018.

CARMO, Vitú do; ALVIM, Zuleika. Chão Fecundo: 100 anos de História do Instituto Agronômico de Campinas. S/Ed, 1987.

DOURADO, G. M. Belle Époque dos Jardins. São Paulo: Editora Senac, 2011.

ENOKIBARA, M. Organizações Dierberger (1893-1940). Paisagem e Ambiente, São Paulo, n. 38, p. 35-54, dec. 2016. ISSN 23595361. Disponível em: <http://www.revistas.usp.br/paam/article/view/112494>. Acesso em: 14 mar 2018. doi:http://dx.doi.org/10.11606/issn.2359-5361.v0i38p35-54.

ENOKIBARA, M.; MODESTO, A. P. M.; ROMERO, L. B.; YENDO, J. O papel do Instituto Agronômico do Estado de São Paulo na divulgação de um repertório vegetal no oeste paulista. In: SALCEDO, R. F. B.; BENINCASA, V.; CHAMMA, P. V. C.; FARIA, O. B. (Orgs.). Reabilitação do patrimônio arquitetônico e edificado e sua dimensão cotidiana. 1. ed. São Paulo: Cultura Acadêmica, 2016. v. 1. p. $91-100$.

GONÇALVES, M. P. Alberto Löfgren e o estudo sobre as “Plantas exóticas introduzidas no estado de São Paulo". 2014. Relatório Final de Bolsa de Iniciação Científica FAPESP, sob orientação da Profa. Dra. Marta Enokibara - Faculdade de Arquitetura, Artes e Comunicação, UNESP, Bauru, 2014 (Processo FAPESP no 2013/13544-9).

GUARALDO, E. Repertório e Identidade. Espaços Públicos em São Paulo, 1890 - 1930. Tese (Doutorado em Arquitetura e Urbanismo)- Faculdade de Arquitetura e Urbanismo, Universidade de São Paulo, São Paulo, 2002.

GUARAldo, E. São Paulo, Paisagem e Paisagismo na Primeira República. Dissertação (Mestrado em Arquitetura e Urbanismo)Faculdade de Arquitetura e Urbanismo, Universidade de São Paulo, São Paulo, 1995. 
INStituto geOgráfico e CARTOgráfico (São Paulo, SP). Mapa político do Estado de São Paulo. São Paulo, 2014. Escala 1:1.000.000.

INSTITUTO DE PESQUISAS TECNOLÓGICAS (São Paulo, SP). Mapa geomorfológico do Estado de São Paulo. São Paulo, 1981. Disponível em: <https://journals.openedition.org/confins/6168?lang=pt>. Acesso em: 03 de março de 2018.

LÖFGREN, A. Notas Sobre as Plantas Exóticas Introduzidas no Estado de São Paulo. São Paulo: Editora da Revista Agricola, 1906. $238 p$.

MAIA, F. P. Introdução ao Estudo de um plano de avenidas para a Cidade de São Paulo. São Paulo: Melhoramentos, 1930.

MODESTO, A. P. M. O Estado e a iniciativa privada na divulgação de um repertório vegetal no Oeste Paulita: o papel do Instituto Agronômico do Estado. 2012. Relatório Final de Bolsa de Iniciação Científica FAPESP, sob orientação da Profa. Dra. Marta Enokibara - Faculdade de Arquitetura, Artes e Comunicação, UNESP, Bauru, 2012 (Processo FAPESP n 2011/07700-2).

MONBEIG, P. Pioneiros e fazendeiros de São Paulo. São Paulo: Editora Hucitec; Editora Polis, 1984.

ROMERO, L. B. O Estado e a iniciativa privada na divulgação de um repertório vegetal no Oeste Paulita: o papel do Instituto Agronômico do Estado. 2012. Relatório Final de Bolsa de Iniciação Científica FAPESP, sob orientação da Profa. Dra. Marta Enokibara - Faculdade de Arquitetura, Artes e Comunicação, UNESP, Bauru, 2012 (Processo FAPESP n o 2011/07625-0).

SÃO PAULO (Estado). Relatório da Secretaria dos Negócios da Agricultura, Commercio e Obras Publicas. 1895-1916.

SCHMIDT, P. M.; REIS, J. Rasgando Horizontes. A Secretaria da Agricultura no seu Cinquentenário. São Paulo: Secretaria da Agricultura, Indústria e Comércio do Estado de São Paulo, 1943.

YENDO, J. O Estado e a iniciativa privada na divulgação de um repertório vegetal no Oeste Paulita: o papel do Instituto Agronômico do Estado. 2011. Relatório Final de Bolsa de Iniciação Científica FAPESP, sob orientação da Profa. Dra. Marta Enokibara - Faculdade de Arquitetura, Artes e Comunicação, UNESP, Bauru, 2012 (Processo FAPESP n o 2010/16872-9).

ZECHINATO, B. P. O Instituto Agronômico do Estado e o repertório vegetal nas cidades do Oeste Paulista no início do século XX. Relatório Final de Bolsa de Iniciação Científica FAPESP, período 2007-2008, sob orientação da Profa. Dra. Marta Enokibara (FAAC / Unesp-Bauru).

\section{SITES CONSULTADOS}

The Plant List (2013), versão 1.1. Disponível em: < http://www.theplantlist.org/>. Acesso em: 01 de março de 2018.

Estações Ferroviárias do Brasil. Disponível em: <http://www.estacoesferroviarias.com.br>. Acesso em: 01 de março de 2018. 